\title{
Further Report on Repeated Impact Tests.
}

\section{By}

Tsuruzô Matsumura, M. E., Kogakuhakushi, Member.

\section{Depth of Notch and Blow Number.}

In the author's previous report (1) $^{(1)}$ on the repeated impact tests ths steel containing $0.25 \%$ carbon showed the maximum resistance and it was remarked that this maximum will probably take place for a different carbon content, if the form and the depth of notch be altered. Further tests were made with the remaining pieces of the same flat bars used in the previous tests, altering the depth of notch.

From each bar (Steel grades No. 1 to No. 6) were cut 24 test pieces $A_{1}$ to $A_{8}, B_{1}$ to $B_{8}$ and $C_{1}$ to $C_{3}$ as shown in Fig. 1.

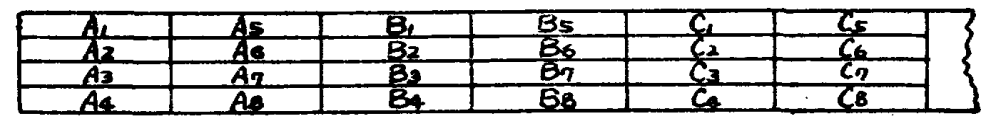

Fig. 1.

The depth of notch was made $2 \mathrm{~mm}$. in the pieces $A_{1}$ to $A_{9}, 2.5 \mathrm{~mm}$. in the pieces $B_{1}$ to $B_{8}$ and $3 \mathrm{~mm}$. in the pieces $C_{1}$ to $C_{\mathrm{s}}$, its form all being circular of $2.5 \mathrm{~mm}$. radius, as shown in Figs. 2 to 4.

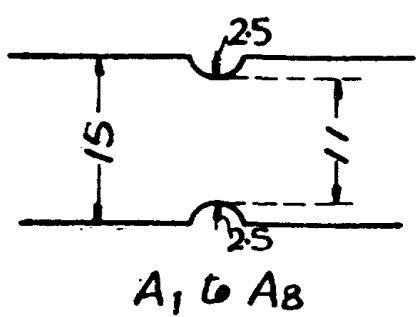

Fig. 2 .

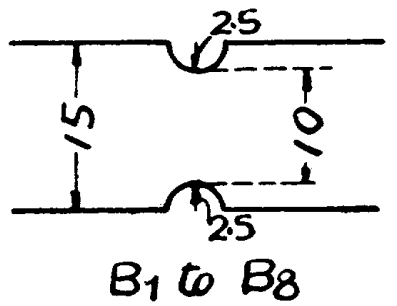

Fig. 3.

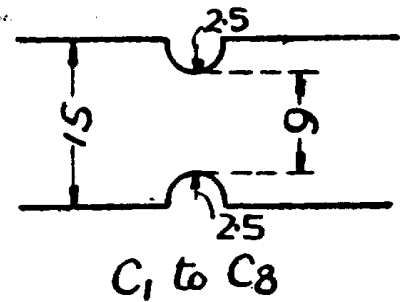

Fig. 4 .

The blow numbers got in the author's repeated impact machine are recorded in

(1) This Journal Vol. XXI, No. 52. 
Tables I to VI. The impact energy of single blow was taken at the rate of $30 \mathrm{cmkg}$. for $10 \mathrm{~mm}$. thickness as before.

TABLE I.

Steel grade No. 1 ; Thickness $11.6 \mathrm{~mm}$.; Impact energy 34.8 cmkg.

\begin{tabular}{|c|c|c|c|c|c|c|}
\hline \multicolumn{2}{|c|}{ Test piece } & Blow number & Test piece & Blow number & Test piece & Blow number \\
\hline \multirow{8}{*}{$A$} & 1 & 639 & \multirow{8}{*}{$\begin{array}{l}3 \\
4 \\
5 \\
6 \\
7 \\
8\end{array}$} & 421 & \multirow{8}{*}{$\begin{array}{l}1 \\
2 \\
3 \\
4 \\
5 \\
6 \\
7 \\
8\end{array}$} & 357 \\
\hline & 2 & 798 & & 446 & & 309 \\
\hline & 3 & 640 & & 438 & & 363 \\
\hline & 4 & 603 & & 432 & & 367 \\
\hline & 5 & 701 & & 456 . & & 346 \\
\hline & 6 & 632 & & 475 & & 403 \\
\hline & 7 & 708 & & 440 & & 325 \\
\hline & 8 & 638 & & 468 & & 337 \\
\hline \multicolumn{2}{|c|}{ mean } & 670 & mean & 447 & mean & 351 \\
\hline
\end{tabular}

TABLE III.

Steel grade No. 2; Thickness $11.2 \mathrm{~mm}$.; Impact energy $33.6 \mathrm{cmkg}$.

\begin{tabular}{|c|c|c|c|c|c|c|}
\hline \multicolumn{2}{|c|}{ Test piece } & Blow number & Test piece & Blow number & Test piece & Blow number \\
\hline \multirow{8}{*}{ A } & 1 & 827 & 1 & 490 & \multirow{8}{*}{$\begin{array}{l}1 \\
2 \\
3 \\
4 \\
5 \\
6 \\
7 \\
8\end{array}$} & 378 \\
\hline & 2 & 729 & 2 & 456 & & 351 \\
\hline & 3 & 609 & 3 & 479 & & 338 \\
\hline & 4 & 794 & 4 & 491 & & 397 \\
\hline & 5 & 804 & 5 & 541 & & 358 \\
\hline & 6 & 844 & 6 & 435 & & 357 \\
\hline & 7 & 796 & 7 & 506 & & 357 \\
\hline & 8 & 793 & 8 & 431 & & 335 \\
\hline \multicolumn{2}{|c|}{ mean } & 775 & mean & 479 & mean & 359 \\
\hline
\end{tabular}




\section{TABLE III.}

Steel grade No. 3 ; Thickness $11.1 \mathrm{~mm}$. ; Impact energy $33.3 \mathrm{cmkg}$.

\begin{tabular}{|c|c|c|c|c|c|}
\hline Test piece & Blow number & Test piece & Blow number & Test piece & Blow number \\
\hline 1 & 777 & 1 & 519 & 1 & 351 \\
\hline 2 & 769 & 2 & 497 & 2 & 359 \\
\hline 3 & 877 & 3 & 503 & 3 & 391 \\
\hline A & 769 & 4 & 434 & 4 & 399 \\
\hline 5 & 979 & 5 & 525 & 5 & 373 \\
\hline 6 & 856 & 6 & 509 & 6 & 385 \\
\hline 7 & 868 & 7 & 623 & 7 & 397 \\
\hline 18 & 825 & 8 & 515 & 8 & 419 \\
\hline mean & 840 & mean & 516 & mean & 384 \\
\hline
\end{tabular}

\section{TABLE IV.}

Steel grade No. 4 ; Thickuess $11.3 \mathrm{~mm}$.; Impact energy $33.9 \mathrm{cmkg}$.

\begin{tabular}{|c|c|c|c|c|c|c|}
\hline \multicolumn{2}{|c|}{ Test piece } & Blow number & Test piece & Blow number & Test piece & Blow number \\
\hline \multirow{8}{*}{ A } & 1 & 653 & \multirow{8}{*}{$\begin{array}{l}6 \\
7 \\
8\end{array}$} & 281 & \multirow{8}{*}{$\begin{array}{l}5 \\
6 \\
7 \\
8\end{array}$} & 282 \\
\hline & 2 & 765 & & 430 & & 306 \\
\hline & 3 & 632 & & 405 & & 271 \\
\hline & 4 & 630 & & 432 & & 324 \\
\hline & 5 & 593 & & 451 & & 297 \\
\hline & 6 & 619 & & 425 & & 320 \\
\hline & 7 & 590 & & 352 & & 323 \\
\hline & 8 & 522 & & 442 & & 318 \\
\hline \multicolumn{2}{|c|}{ mean } & 626 & mean & 402 & mean & 305 \\
\hline
\end{tabular}




\section{Table $V$.}

Steel grade No. 5; Thickness $11.5 \mathrm{~mm}$; Impact energy $34.5 \mathrm{cmkg}$.

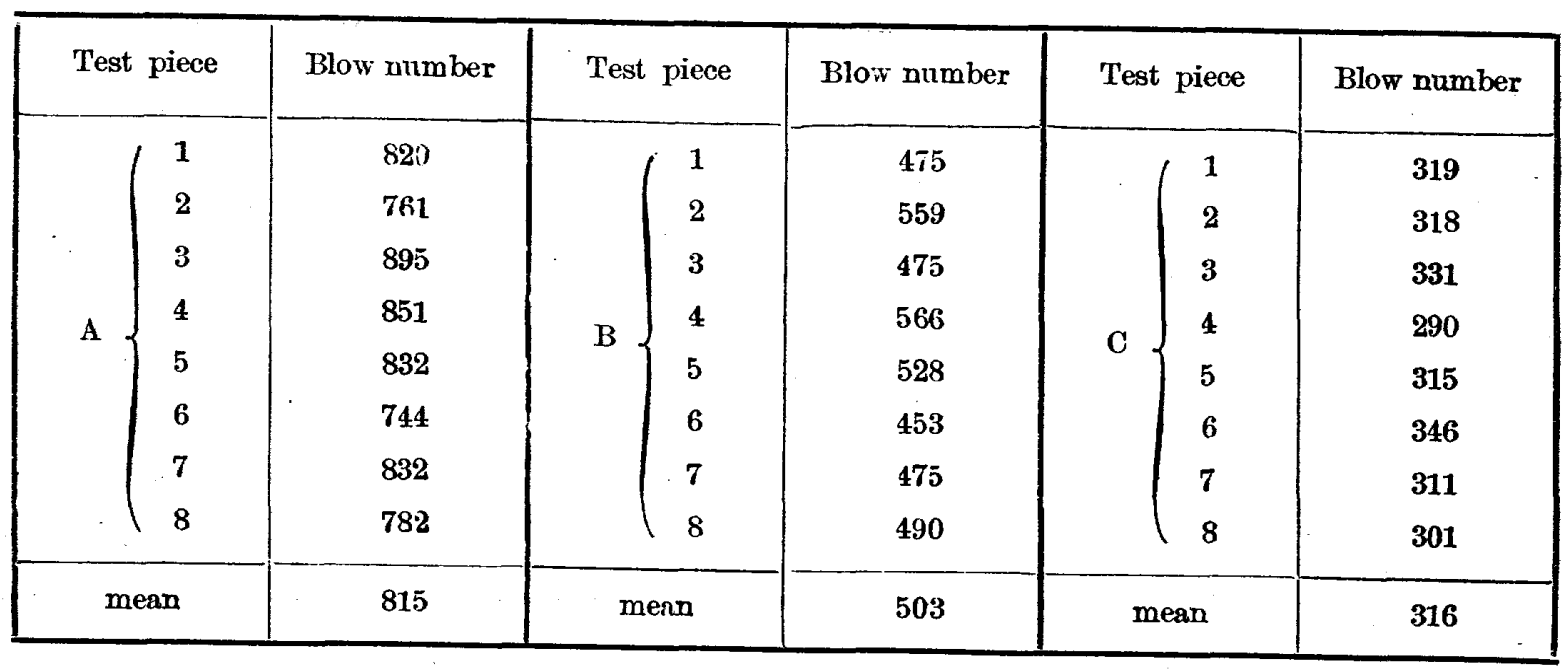

Table VI.

Steel grade No. 6 ; Thickness 11.45 mm.; Impact energy 34.35 cmkg.

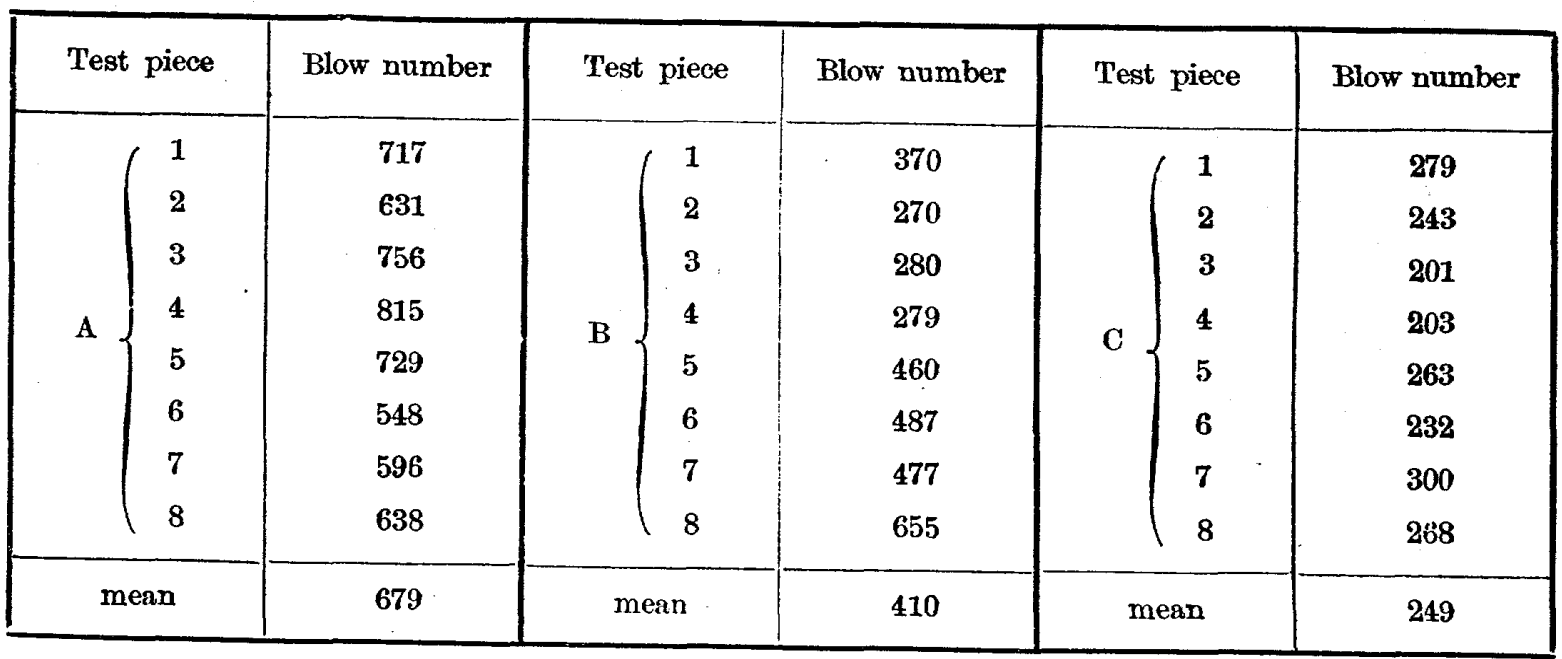


The mean blow numbers are plotted in Fig. 5, taking percentages of carbon as abscissae.

From Fig. 5 we observe that :

1. The steel grade No. 3 has the maximum resistance in all cases.

2. Increasing the depth of notch the diagram is flattened, the peak of the maximum becomes lower and the blow number falls at a greater rate as a steel contains more carbon.

The consequence of the item 2 must be the tendency of sifting the maximum point towards the left, but it is very small as not apparent in Fig. 5, so that the influence of depth of notch on the position of the maximum point may be disregarded.

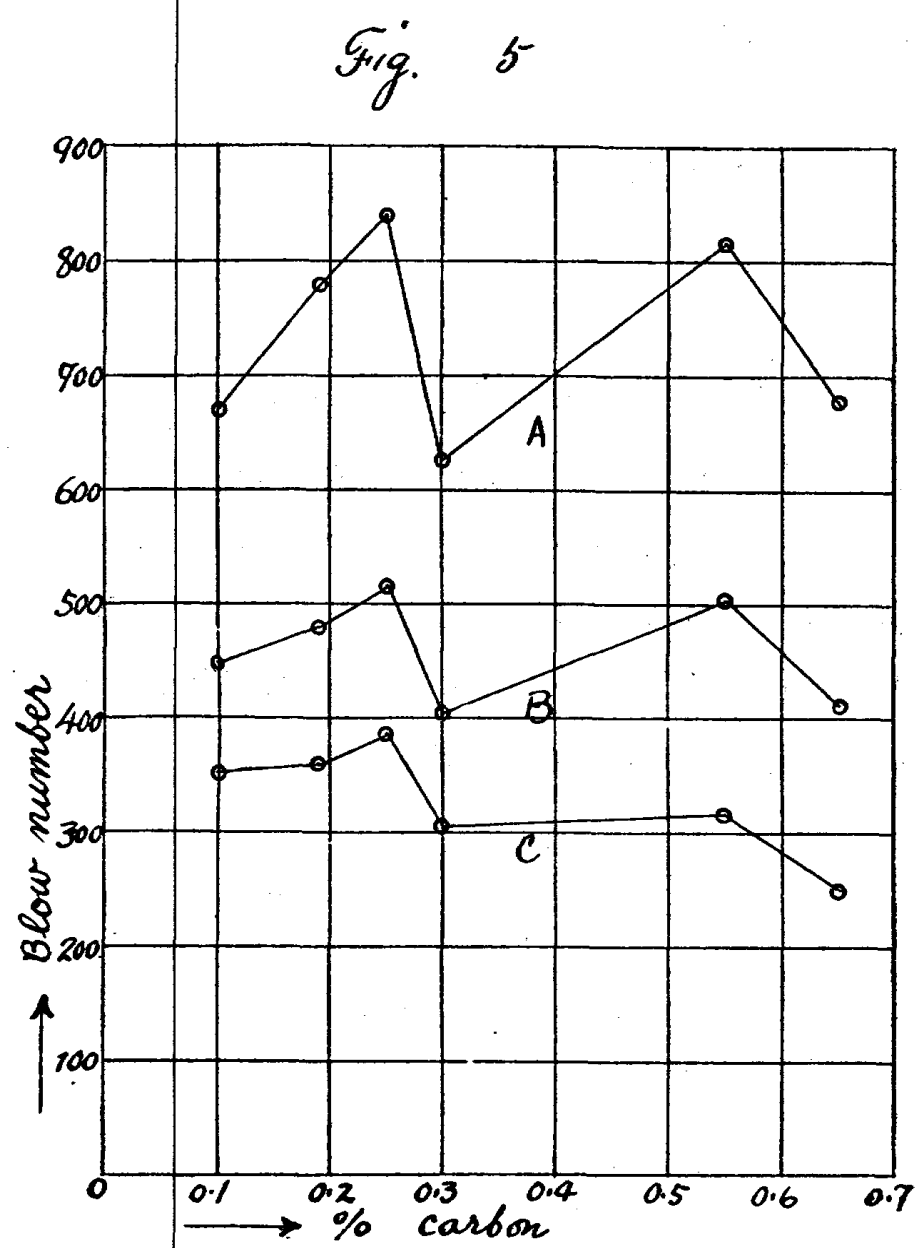

One thing that will not escape from our notice in the present three serfes of teat as well as the series in the former report is that, the steel grade No. 4 has comparatively a very low resistance. This cansed the author to suspect some defects in its structure and naturally led him to microscopical observations.

The test pieces whose blow number is near to the mean blow number were selected and ohserved under microscopo. Figs. 6 to 11 show the structure of the piecas 1C5, $2 \mathrm{C} 6,3 \mathrm{C} 3,4 \mathrm{C} 5,5 \mathrm{C} 1$ and $6 \mathrm{C2}$ at the section $a b$, Fig. 12, near the fracture.

The piece 4C5 shows a somewhat irregular distribution of partite particles, while 
the tendency of the piece $3 \mathrm{C} 3$ to the Widmanstättian structure, characteristic to steel in cast condition or that subject to a deficient forging or rolling, is striking.

Figs. 13 to 16 show the structure of the

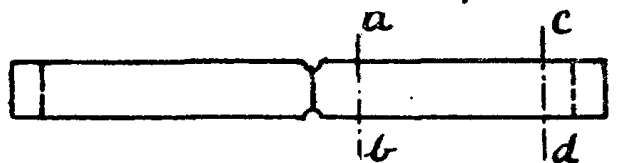

Fig. 12. pieces $3 \mathrm{C} 5,3 \mathrm{C} 6,4 \mathrm{C2}$ and $4 \mathrm{C} 8$ at the section $a b$ near the fracture and Figs. 17 to 20 that of the same pieces at the section $c d$ near the end.

Comparing the photographs of the grades No. 3 and No. 4, if a defective structure have influences upon the resistance to repeated impacts, the grade No. 3 would, to the contrary to the fact, have shown a lower resistance than No. 4. We have, therefore, to look for the other causes.

A further trial made was the determination of sulphur and phosphorus contents. Table VII shows the results of analysis.

'TABLE VII.

\begin{tabular}{|c|c|c|c|c|c|c|}
\hline Test piece & $1 \mathrm{C} 5$ & $2 \mathrm{C6}$ & $3 \mathrm{C} \mathrm{3}$ & $4 \mathrm{C} 5$ & $5 \mathrm{C} 1$ & $6 \mathrm{C2}$ \\
\hline Blow number & 346 & 357 & 391 & 297 & 319 & 243 \\
C \% & 0.102 & 0.19 & 0.25 & 0.30 & 0.55 & 0.65 \\
P " & 0.025 & 0.040 & 0.067 & 0.075 & 0.045 & 0.049 \\
S & 0.034 & 0.059 & 0.024 & 0.039 & 0.061 & 0.041 \\
\hline
\end{tabular}

The grade No. 4 contains $0.075 \%$ phosphorus, while that No. 3 only $0.067 \%$. The other grades contain much less percentage of phosphorus.

Comparing the grades No. 3 and No. 4 we may assume for the present that a more phosphorus content in conjunction with a greater percentage of carbon is at least a cause of weakness of the grade No. 4 .

\section{Phosphoras Content and Blow Number.}

In the foregoing test a rough idea on the relation between the phosphorus content and the resistance to repeated impacts was obtained. With a view to further research 
on the relation the comparative tests on steel bars of possibly uniform composition, but with different amounts of phosphorus were intended. The Osaka Arsenal was kind enough to undertake the manufacture and supply of the bars. They are 7 in kinds and all $\frac{3}{4}$ in. in diameter. The result of analysis by the arsenal is reproduced in Table VIII.

TABLE VIII.

\begin{tabular}{|c|c|c|c|c|c|c|}
\hline No. & $\mathrm{C}$ & $\mathrm{Si}$ & $\mathrm{P}$ & $\mathrm{S}$ & $\mathrm{M}$ & $\mathrm{Cu}$ \\
\hline 2 & 0.322 & 0.123 & 0.019 & 0.017 & 0.825 & 0.14 \\
3 & 0.331 & 0.222 & 0.029 & 0.014 & 0.614 & - \\
4 & 0.276 & 0.231 & 0.037 & 0.016 & - & - \\
5 & 0.312 & 0.242 & 0.048 & 0.014 & 0.507 & 0.10 \\
6 & 0.267 & 0.244 & 0.065 & 0.014 & 0.482 & 0.10 \\
7 & 0.324 & 0.291 & 0.078 & 0.014 & 0.457 & 0.13 \\
8 & 0.268 & 0.272 & 0.089 & 0.016 & 0.490 & 0.13 \\
\hline
\end{tabular}

From each bar three test pieces for tension and eight for repeated impact were taken, the latter being of the form as shown in Fig. 21.

The result of tension tests is recorded in Table IX and that of repeated impact tests in Table $\mathrm{X}$. They are shown gra-

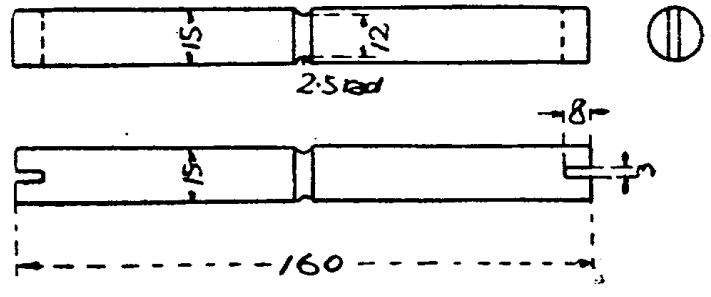

Fig. 21. phically in Fig. 22.

TABLE IX.

Test piece $13 \mathrm{~mm}$. dia $\times 50 \mathrm{~mm}$. gange length.

\begin{tabular}{|c|c|c|c|c|c|}
\hline Bar No. & $\begin{array}{c}\text { No. of tests } \\
\text { from which } \\
\text { the menn } \\
\text { is taken }\end{array}$ & $\begin{array}{c}\text { Strength } \\
\mathbf{k g} / \mathrm{cm}^{2}\end{array}$ & $\begin{array}{c}\text { Elongation } \\
\%\end{array}$ & $\begin{array}{c}\text { Area } \\
\text { contraction } \\
\%\end{array}$ & $\begin{array}{c}\text { Yielding stress } \\
\mathrm{kg}^{2} \mathrm{~cm}^{2}\end{array}$ \\
\hline 3 & $\mathbf{2}$ & 5482 & 30.6 & 55.0 & 3390 \\
4 & 2 & 5946 & 35.8 & 65.8 & 3459 \\
5 & 3 & 5609 & 32.0 & 61.1 & 3702 \\
6 & 3 & 5483 & 31.1 & 59.7 & 3676 \\
7 & 3 & 5863 & 31.5 & 56.7 & 3814 \\
\hline
\end{tabular}


Table $X$.

Blow numbers.

\begin{tabular}{|c|c|c|c|c|c|c|c|c|c|c|c|}
\hline \multirow{2}{*}{$\begin{array}{l}\text { Bar } \\
\text { No. }\end{array}$} & \multirow{2}{*}{$\begin{array}{c}\text { Phosphorus } \\
\%\end{array}$} & \multicolumn{9}{|c|}{ Test piece } & \multirow{2}{*}{ Mern } \\
\hline & & A & B & $\mathrm{C}$ & $\mathrm{D}$ & $E$ & F & G & $\mathrm{H}$ & $\mathrm{K}$ & \\
\hline 2 & 0.019 & 746 & 960 & 1041 & 871 & 960 & 898 & 833 & 1180 & 893 & 931 \\
\hline 3 & 0.028 & 1011 & 974 & 843 & 1149 & 1471 & 1233 & 944 & 1235 & 797 & 1073 \\
\hline 4 & 0.037 & 1058 & 897 & 1101 & 1156 & 1179 & 1105 & 1022 & 1005 & 974 & 1055 \\
\hline 5 & $0.0 \pm 8$ & 1116 & 1055 & 1160 & 929 & 1223 & 879 & 1175 & 1031 & 853 & 1046 \\
\hline 6 & 0.065 & 1107 & 889 & 1037 & 1183 & 1136 & 1267 & 1235 & 1252 & 1251 & 1150 \\
\hline 7 & 0.078 & 740 & 776 & 689 & 786 & 935 & 669 & 1084 & 878 & 700 & 806 \\
\hline 8 & 0.088 & 905 & 820 & 999 & 921 & 595 & 717 & 782 & 947 & 1027 & 857 \\
\hline
\end{tabular}

Fig. 22

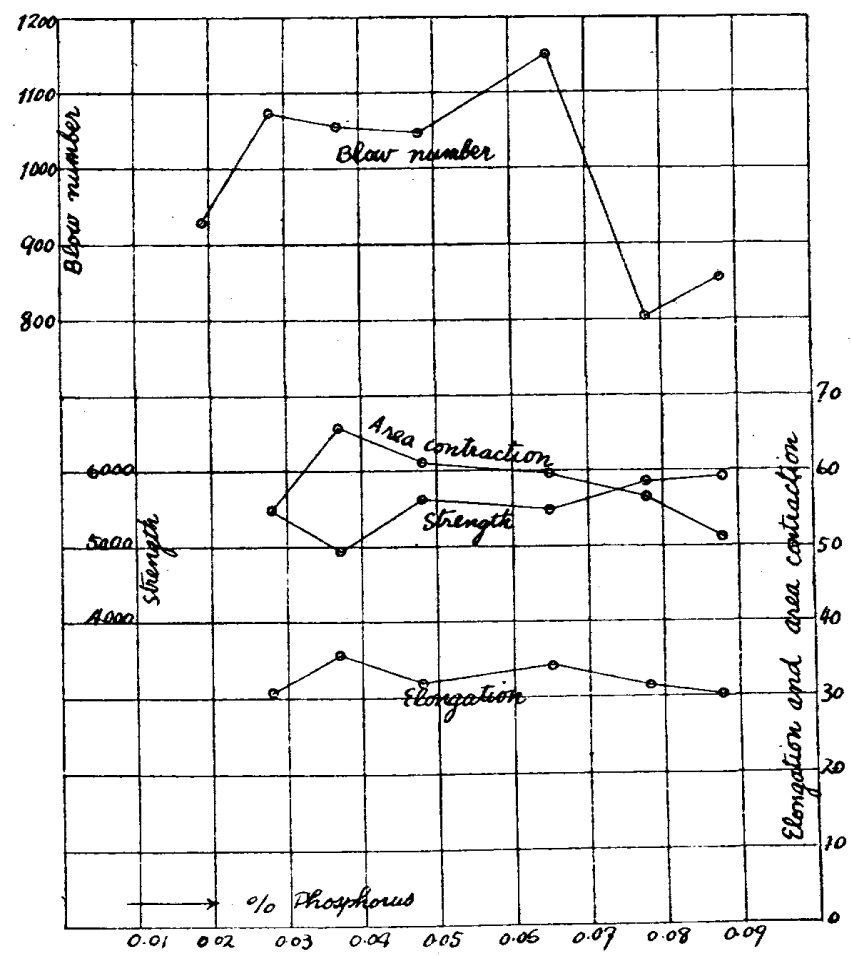

From Fig. 22 it may be assumed that in the mild steel containing about $0.3 \%$ carbon the effect of phosphorus on the resis'ance to repeated impacts is not appreciable, 
so far als its content is less thim abont $0.07 \%$ and first when this limit is exceeded, the resistance is spoiled.

\section{Blow Number and Upton-Lewis' Toughness Number.}

A comparison of result of the author's test with that of Upton-Lewis tonghness test was tried. As the test materials basic steel round bars $1 \frac{3}{8}$ ins. diameter $\times 1 \mathrm{~m}$. length were supplied by the Imperial Steel Works of Yawata. To the steel bars a list of analysis made in the Steel Works was annexed, which will be reproduced in Table XI.

TABLE XI.

\begin{tabular}{|c|c|c|c|c|c|c|}
\hline \multirow{2}{*}{$\begin{array}{l}\text { Bar } \\
\text { No. }\end{array}$} & \multirow{2}{*}{$\begin{array}{c}\text { Number of } \\
\text { melt }\end{array}$} & \multicolumn{5}{|c|}{ Analysis } \\
\hline & & C & Mn &. $\mathrm{Si}$ & 1 & S \\
\hline 1 & 89975 & 0.10 & 0.36 & - & 0.022 & 0.0037 \\
\hline 2 & 90289 & 0.15 & 0.37 & - & 0.039 & 0.032 \\
\hline 3 & 91144 & 0.20 & 0.45 & - & 0.023 & 0.038 \\
\hline 4 & 90907 & 0.29 & 0.56 & 1.78 & 0.018 & $0.04 \mathrm{l}$ \\
\hline 5 & 73892 & 0.35 & 0.78 & 1.88 & 0.034 & 0.019 \\
\hline 6 & 90141 & 0.40 & 0.71 & 1.50 & 0.044 & 0.023 \\
\hline 7 & 90577 & 0.46 & 0.80 & 1.87 & 0.032 & 0.036 \\
\hline 8 & 89608 & 0.50 & 0.75 & 1.68 & 0.024 & 0.011 \\
\hline 9 & 89635 & 0.55 & 0.69 & 1.00 & 0.621 & 0.031 \\
\hline 10 & 90749 & 0.59 & 0.54 & 2.44 & 0.021 & 0.046 \\
\hline 11 & 84467 & 0.65 & 0.67 & 2.37 & 0.043 & 0.029 \\
\hline 12 & 91061 & 0.71 & 0.59 & - $\quad 2.16$ & 0.015 & 0.035 \\
\hline
\end{tabular}

Each bar was cut into two lengths and forged flat under a stean hammer in the college workshop, one to about $15 \mathrm{~mm}$. thickness for the repented inpact pitces and the other to about $12 \mathrm{~mm}$. for the Upton-Lewis' pieces. Atmos' care was taken to forge all bars under equal conditions, that is to forge in one heating from the dus initial temperatture, keeping blow powers of hammer alike and to cool in the atmosphere in a sinilar manner.

From e.ch bar six repeated impact pieces and four Upton-Lewis' picce; were oblained as in Fig. 23. 
The Upton-Iewis' machine was adjusted to the crank radius of $\frac{3}{4}$ in. Each test piece was tested three times, that is broken in three sections and the intermediate

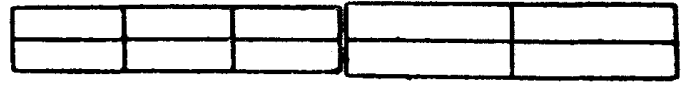

Fig. 23. repetition number was taken.

Tables XII and XIII give the results of the author's and the Upton-Lewis' tests respectively. Plotting as usual the mean values in these tables in dependence on carbon content and drawing curves we get Fig. 24 .

TABLE XII.

Blow numbers.

Test piece rectangular and $10 \mathrm{~mm}$. in thickness ; Impact energy $30 \mathrm{cmkg}$.

\begin{tabular}{|c|c|c|c|c|c|c|c|c|}
\hline \multirow{2}{*}{$\begin{array}{c}\text { Bar } \\
\text { Bo. }\end{array}$} & \multirow{2}{*}{$\begin{array}{c}\text { Carbon } \\
\%\end{array}$} & \multicolumn{6}{|c|}{ Mark } & \multirow{2}{*}{ Mean } \\
\hline & & A & $\mathbf{B}$ & C & $\mathbf{D}$ & $\mathbf{E}$ & $\mathbf{F}$ & \\
\hline 1 & 0.10 & 303 & 350 & 362 & 298 & 412 & 337 & 334 \\
\hline 2 & 0.15 & 367 & 362 & 322 & 422 & 328 & 345 & 358 \\
\hline 3 & 0.20 & 298 & 319 & 323 & 292 & 278 & 294 & 301 \\
\hline 4 & 0.29 & 365 & 281 & 355 & 355 & 279 & 304 & 323 \\
\hline 5 & 0.35 & 440 & 451 & 416 & 447 & $46 \check{~}$ & 431 & 442 \\
\hline 6 & 0.40 & 356 & 368 & 377 & 399 & 475 & 421 & 401 \\
\hline 7 & 0.46 & 376 & 419 & 405 & 355 & 534 & 424 & 419 \\
\hline 8 & 0.50 & 281 & 288 & 274 & 287 & 309 & 295 & 289 \\
\hline 9 & 0.55 & 307 & 310 & 278 & 293 & 265 & 231 & 281 \\
\hline 10 & 0.59 & 143 & 102 & 112 & 142 & 119 & 114 & 122 \\
\hline 11 & 0.65 & 66 & 157 & 119 & 132 & 139 & 72 & 114 \\
\hline 12 & 0.71 & 108 & 116 & 122 & 144 & 113 & 133 & 123 \\
\hline
\end{tabular}




\section{TABLE XIII.}

'Test piece $1 \mathrm{in}$. in width $\times \frac{1}{4} \mathrm{in}$. in thickness.

$\mathbf{n}=$ number of repea'ed bendings and $\mathbf{M}=$ mean moment resisted by the test piece in in-lbs.

\begin{tabular}{|c|c|c|c|c|c|c|c|c|c|c|}
\hline \multirow{2}{*}{$\begin{array}{l}\text { Bar } \\
\text { No. }\end{array}$} & \multirow{2}{*}{$\begin{array}{c}\text { Carbon } \\
\%\end{array}$} & \multicolumn{2}{|c|}{$G$} & \multicolumn{2}{|c|}{$\mathbf{H}$} & \multicolumn{2}{|c|}{$\mathrm{K}$} & \multicolumn{2}{|c|}{ L } & \multirow{2}{*}{$\begin{array}{c}\text { Mean } \\
\text { nMI } \\
\text { (rounded) }\end{array}$} \\
\hline & & $\mathbf{n}$ & II & n & II & n & $\mathbf{M}$ & $\mathbf{n}$ & M & \\
\hline 1 & 0.10 & 1470 & $3 \cdot 3$ & $130 \overline{5}$ & 305 & 1380 & 303 & 1375 & 321 & 426000 \\
\hline 2 & 0.15 & 1353 & 231 & 1485 & 300 & 1275 & 369 & 1380 & 309 & 413000 \\
\hline 3 & 0.20 & 930 & 384 & 1190 & 302 & 1405 & 378 & 1245 & 313 & 409000 \\
\hline 4 & 0.29 & 1316 & 345 & 930 & 381 & 705 & $3 \epsilon 0$ & 1216 & 321 & 364000 \\
\hline 5 & 0.35 & 1408 & 454 & 1380 & 429 & 1068 & 409 & 990 & 444 & 527030 \\
\hline 6 & 0.40 & 1131 & 411 & $1 £ 66$ & 415 & 973 & 399 & 1040 & 409 & 461000 \\
\hline 7 & 0.46 & 1605 & $3: 10$ & 1535 & 399 & 1005 & 376 & 1192 & 374 & 516000 \\
\hline 8 & 0.50 & 985 & 460 & 820 & 381 & 1290 & 366 & $11: 60$ & 437 & 426000 \\
\hline 9 & 0.55 & 1200 & 450 & 850 & 460 & 970 & 370 & 1400 & 387 & 458000 \\
\hline 10 & 0.59 & 113 & 456 & 1129 & 439 & 1063 & 450 & 744 & 444 & 454000 \\
\hline 11 & 0.65 & 744 & 507 & 593 & 501 & 554 & 431 & 770 & 443 & 314000 \\
\hline 12 & 0.71 & 945 & 580 & 940 & 419 & 933 & 411 & 905 & 456 & 387000 \\
\hline
\end{tabular}

In the Upton-Lewis' test some of the test pieces endure, before breaking asunder, a tolerably great number of repeated bendings, without imparting any compression to the load indicating springs. In counting the number of repetition $\mathrm{n}$ such bendings were excluded.

As seen from Fig. 24 both the blow number as well as the Upton-Lewis' tonghness number $\mathrm{n} \mathrm{M}$ show sinilarly the maximum value for about the same carbon content, but the blow number falls at a fuster rate than $\mathrm{n} \mathrm{M}$ as the amount of carbon increases.

Comparing the result of the present repaated impact test with that of the previous

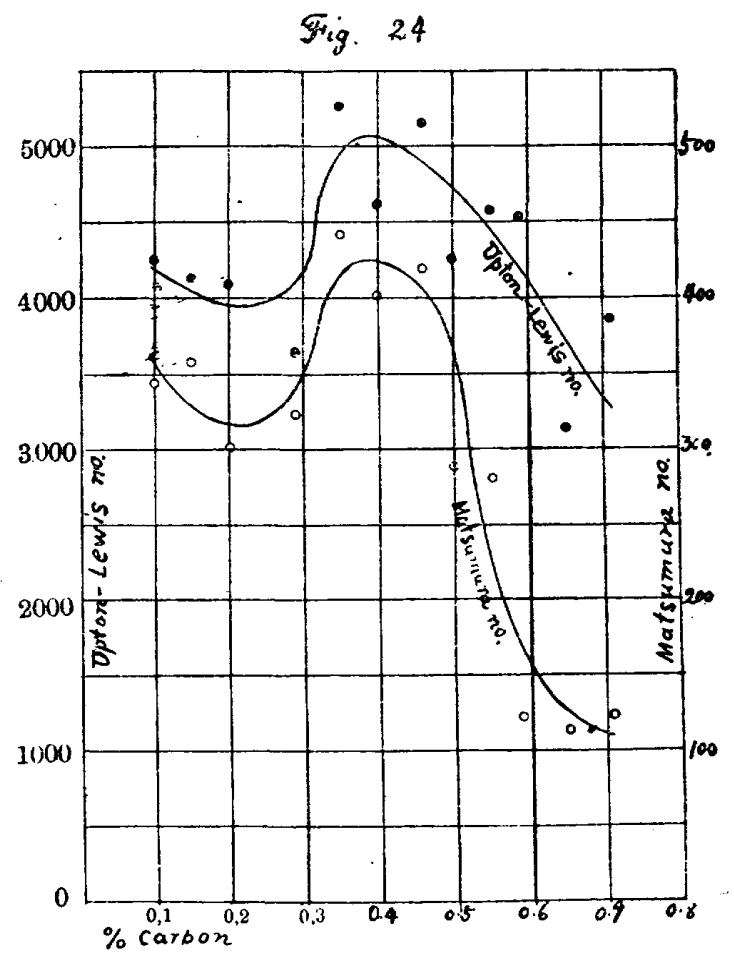


test the percentage of carbon, for which the maximum resistance takes place, is not exactly alike. It was previously $0.25 \%$, while is here 0.35 to $0.45 \%$. Tha discordance is probably due to the influence of impurities other than carbon, especially of phosphorus.

The occurrence of the maximum resistance is also observed when test is made with special steels quenched from above $A_{3}$, point and annealed at different temperatures. Some of the results of repeated impact and other tests ${ }^{(1)}$ made by Cominumder Yamashita of Yokosuka may be quoted here. Figs. 25 and 26 show the relation batween aunealing temperature and mechanical properties.
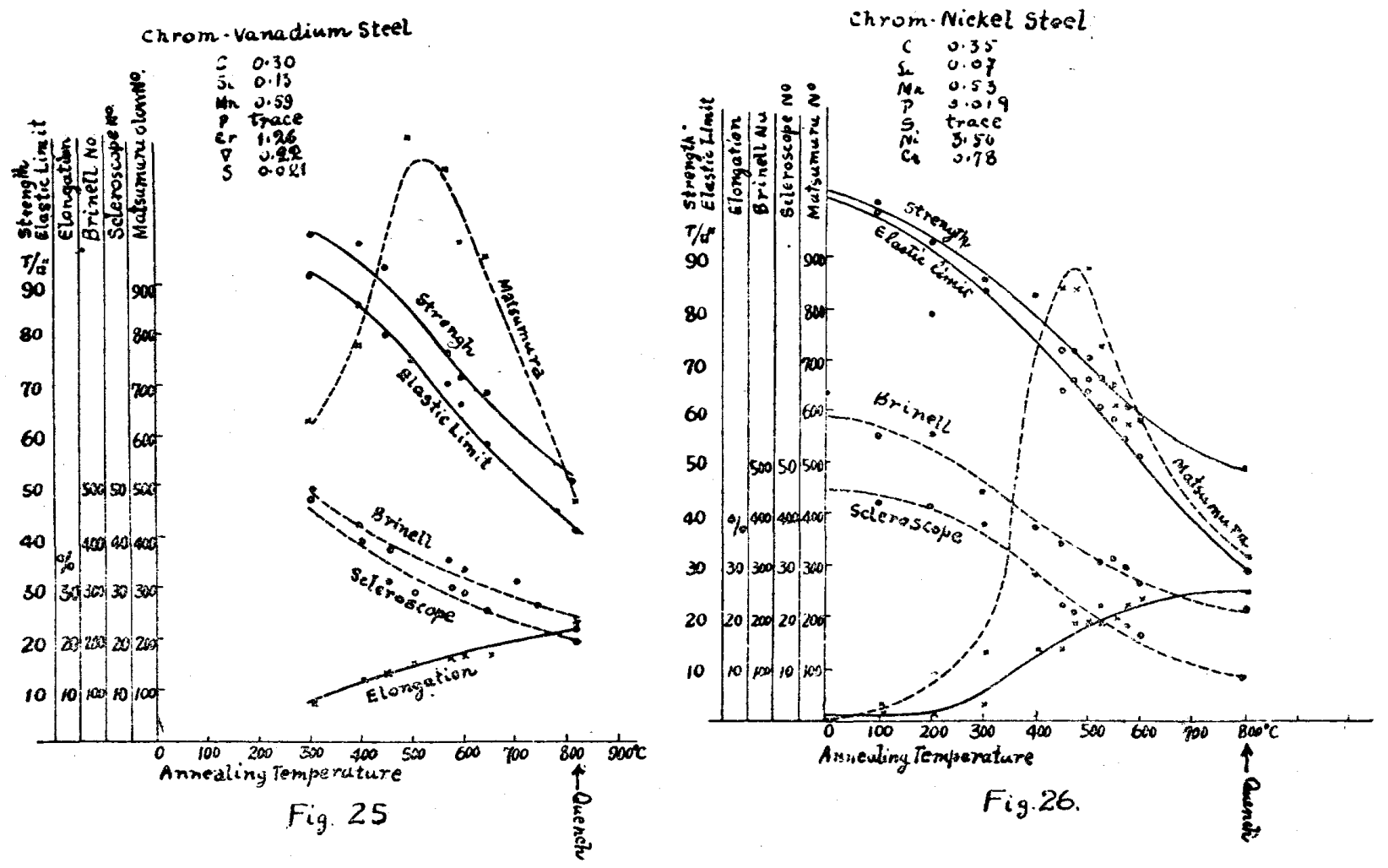

Figs. 24 to 26 show that the resistance to repented impacts varies very considerably in dependence on carbon content in ordinary steel and in dependence on thermal treatnent in special steel. This accounts for the importince of repeated inpact test for the material used as a construction part nore or less subject to shock.

\section{Impact Eneræy and Blow Number.}

From a mild steel round bar of ${ }_{4}^{3} \mathrm{in}$. in diameter got frim mirket, 18 ronnd test.

(1) This Journal Vol. XXIV, No. 65. 
pieces, as shown in Fig. 21, were taken and tested in the repeated impact machine, each under a different impact energy. The result is recorded in Table XIV and are shown by points in Fig. 27.

TABLE XIV.

\begin{tabular}{|c|c|c|c|c|c|}
\hline $\begin{array}{c}\text { Impact energy } \\
\text { cmkg. }\end{array}$ & Blow number & $\begin{array}{c}\text { Impact energy } \\
\text { cmkg. }\end{array}$ & Blow number & $\begin{array}{c}\text { Impact energy } \\
\text { cmlkg. }\end{array}$ & Blow number \\
\cline { 2 - 5 } 20 & 2063 & 28 & 1248 & 40 & 665 \\
21 & 1950 & 30 & 1016 & 42 & 670 \\
22 & 2208 & 32 & 1039 & 44 & .571 \\
23 & 1600 & 34 & 1026 & 46 & 519 \\
24 & 1513 & 36 & 872 & 48 & 563 \\
26 & 1431 & 38 & 669 & 50 & 436 \\
\hline
\end{tabular}

The result may be formulized to

$$
n=\frac{30800}{e^{1 . \rho_{0}}}
$$

where $n$ represents the blow number and $e$ the impact energy in cmkg. The curve in Fig. 27 was drawn according to this formula.

\section{Summary.}

1. The remaining pieces of the same flat bars in the previous repeated impact rest were utilized for further tests to find the effect of depth of notch on the result and it is ascertained that increasing depth of notch the blow number falls at a greater tate as a steel contains more carbon. As Frig. 27.

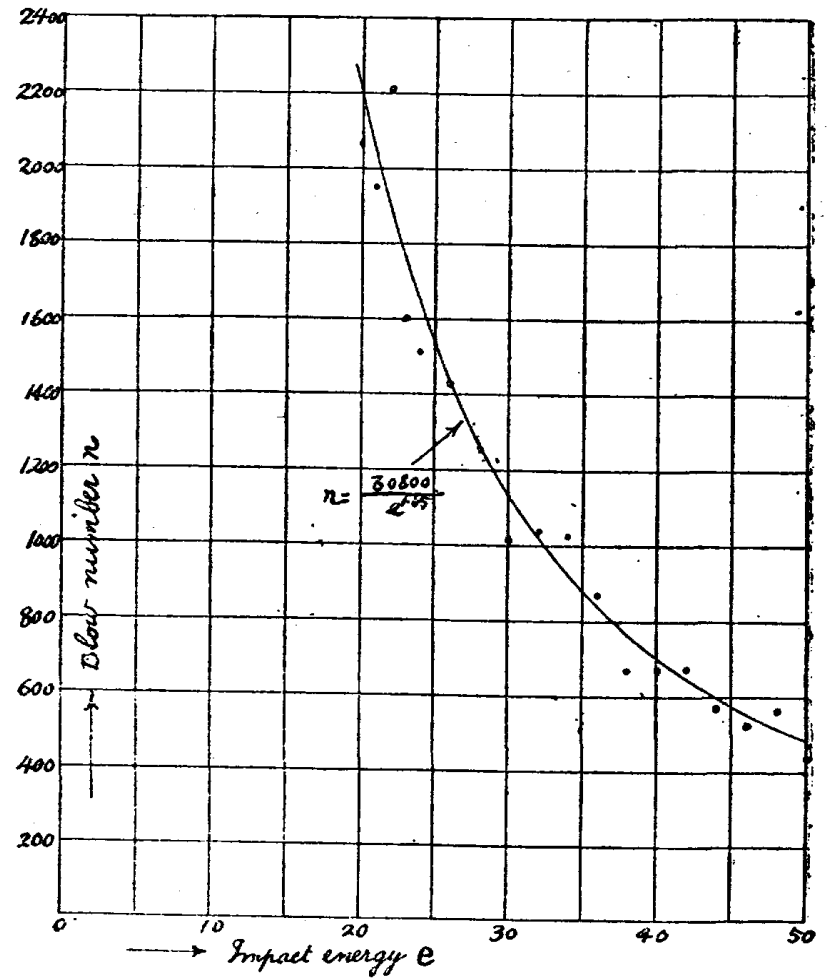

the consequence the maximum resistance must take place for a smaller carbon content but the influence is very small and may be disregarded.

2. The comparative tests on sted bars of possibly uniform composition but with 
different amount of phosphorus were performed and it is found that in the mild steel containing about $0.3 \%$ carbon the effect of phosphorus on the resistance to repeated impacts is not appreciable, so far as its content is less than about $0.07 \%$ and first when this limit is exceeded, the resistance is spoiled.

3. A comparison of the blow number with the Upton-Lewis' toughness number n NI for the steel grades containing from 0.1 to $0.71 \%$ of carbon was made. Both the blow number as well as the toughness number $\mathrm{n} \mathbf{M}$ show similarly the maximun value for about the same carbon content, but the blow number falls at a faster rate than $\mathbf{n} \mathbf{M}$ as the amount of carbon increases.

4. Test pieces cut from a mild steel bar were tested in the repeated inpact machine, each under a different impact energy and the result is formulized to

$$
n=\frac{30800}{e^{1,50}}
$$

$n$ being the blow number and $e$ the impact energy in cmkg.

In conclusion the author expresses his hearty thanks to the Imperial Steel Works and the Osaka Arsenal for supplying the test materials and to Mr. Tsunejiro Nakai for the zealous assistance throughout the work. 
Pl. 1 .

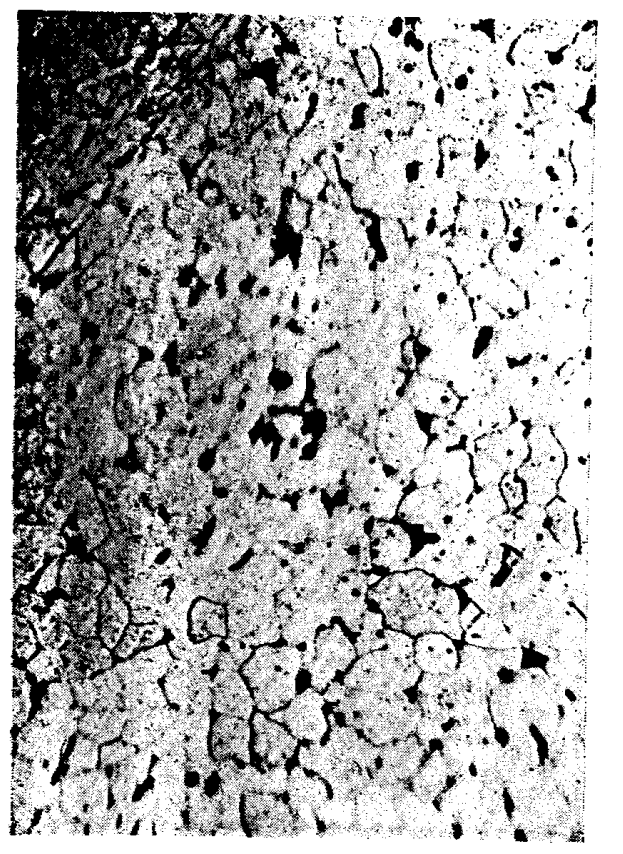

Fig. 6.

Test piece 1C5. Blow no. 346. 200 dias.

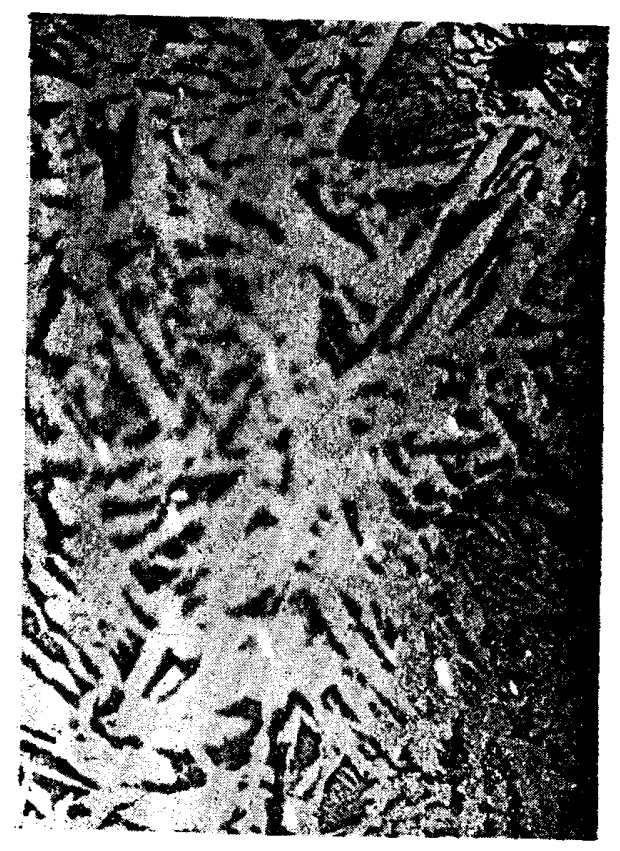

Fig. 8.

Test piece 3C3. Blow no. 391. 200 dias.

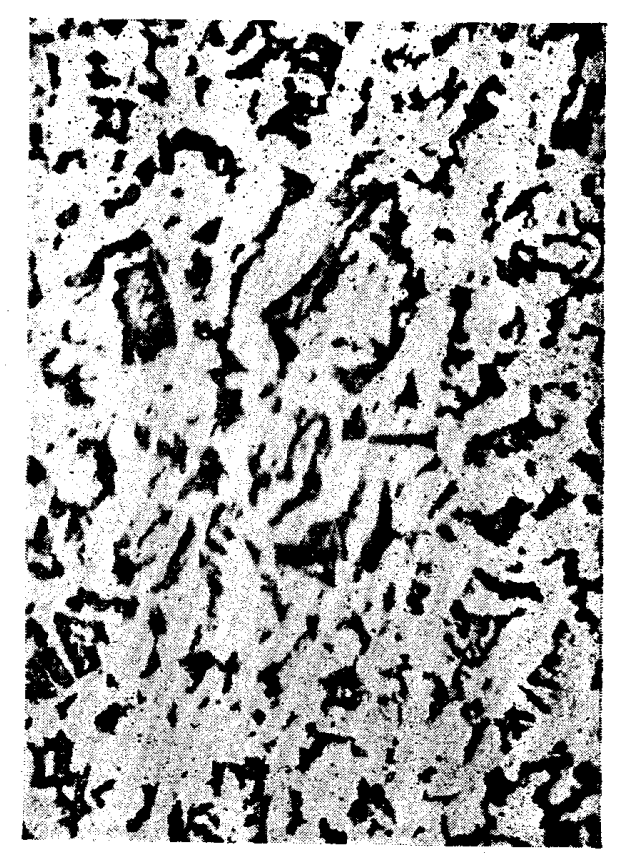

Fig. 7.

Test piece 2C6. Blow no. 357. 200 dias.

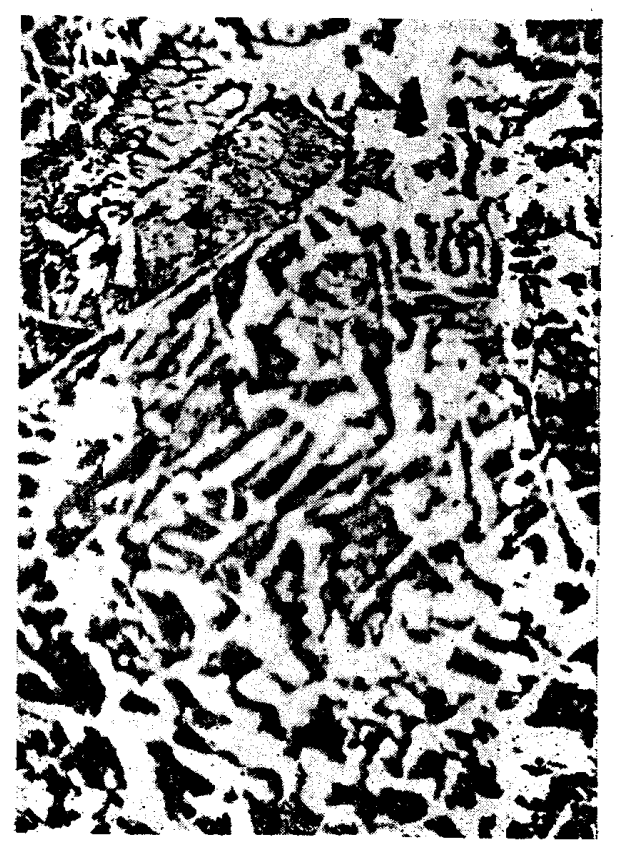

Fig. 9.

Test piece 4C5. Blow no. 297. 200 dins. 
Pl. 2.

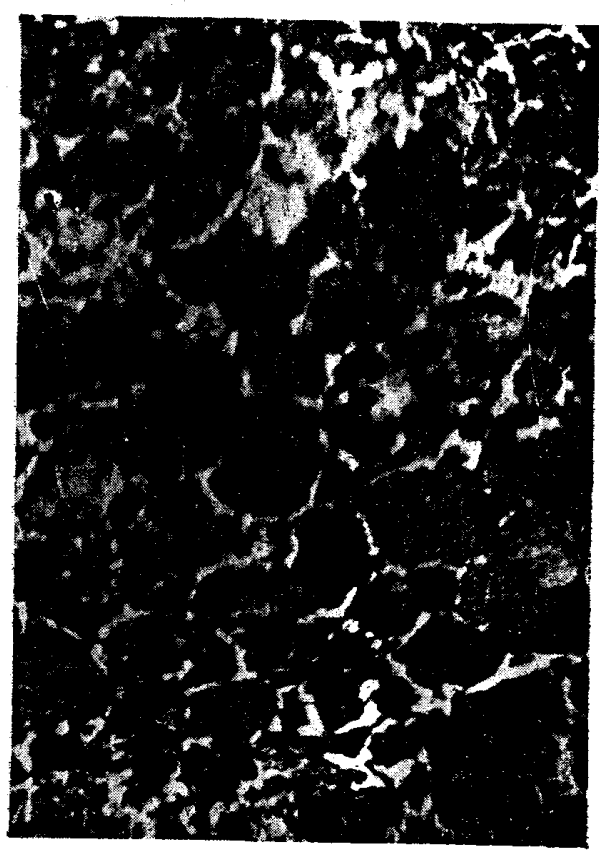

Fig. 10.

Test piece 5C1. Blow no. 319. 200 dias.

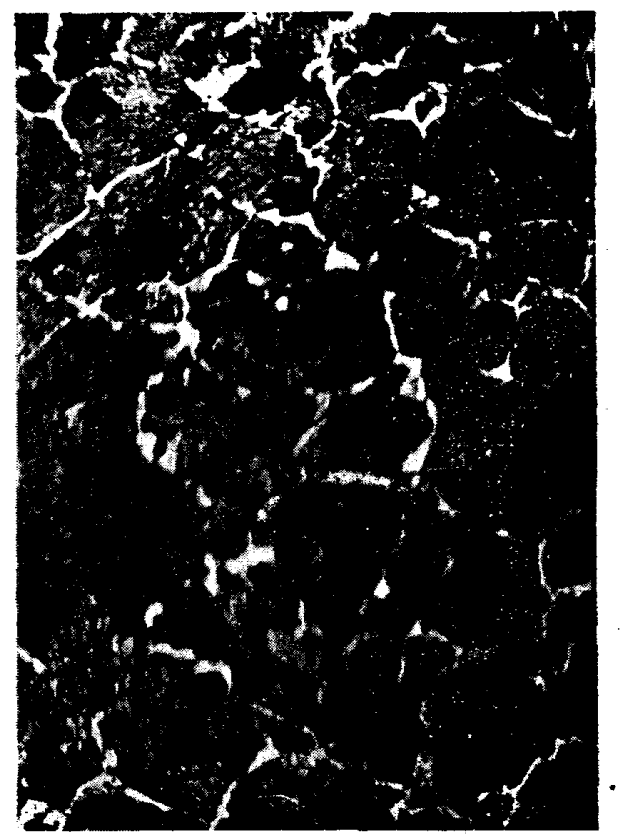

Fig. 11.

Test riece 6C2. Blow no. 243. 200 dias. 
Pl. 3.

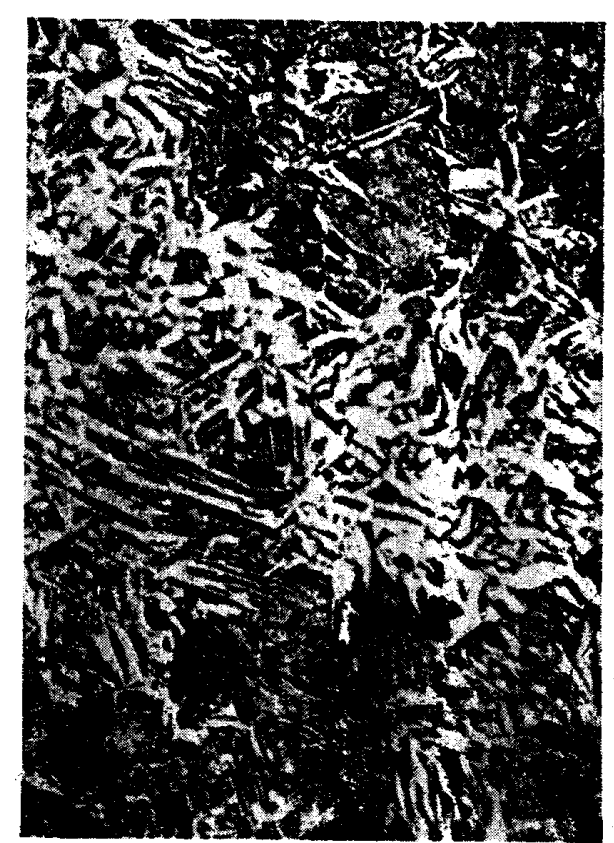

Fig. 13.

Test piece 3C5. Blow no. 373. 200 dias.

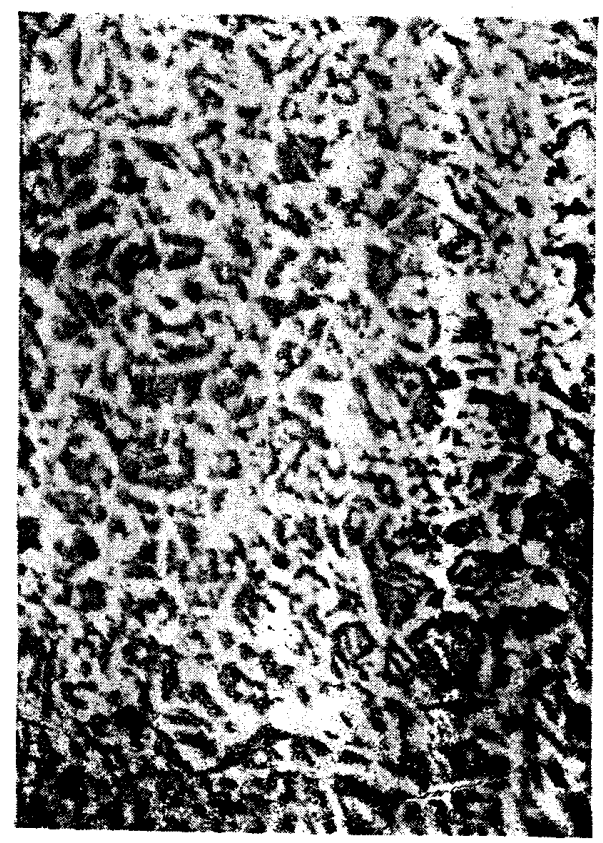

Fig. 15.

Test. piece 4C2. Blow no. 306 . 200 dias.

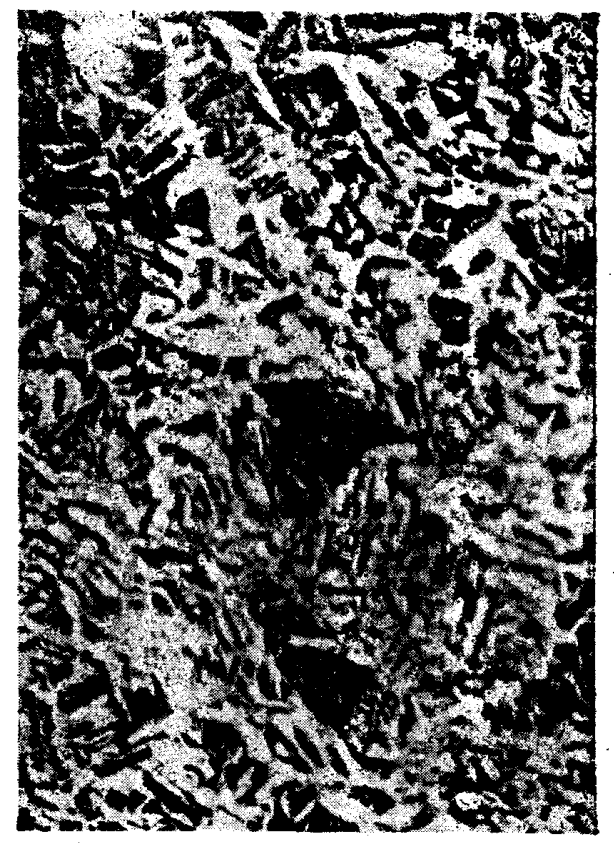

Fig. 14.

Test piece 3C6. Blow no. 385. 200 dias.

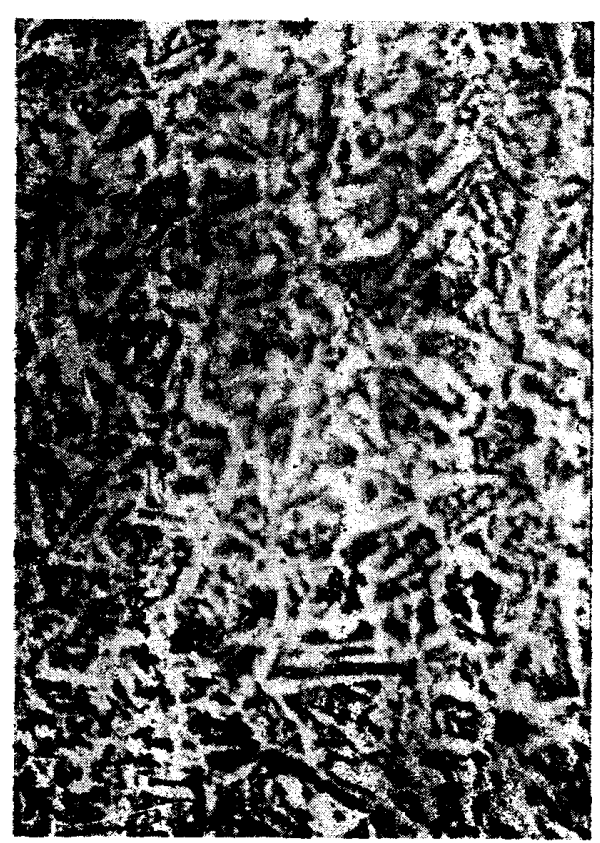

Fig. 16.

Test piece 4C8. Blow no. 318 .

200 dias. 
Pl. 4.

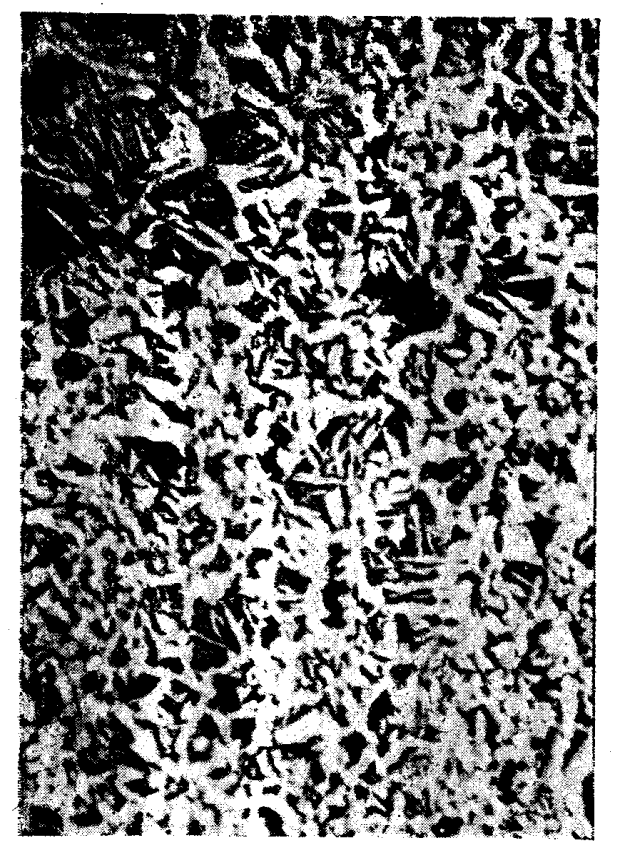

Fig. 17.

Test piece 3C5. Blow no. 373. 200 dias.

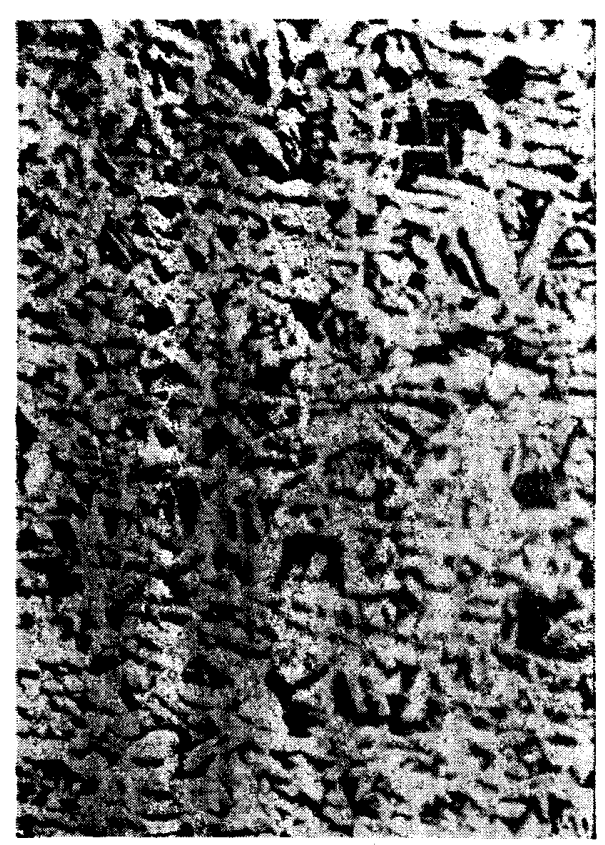

Fig. 18.

Test piece 3C6. Blow no. 385.

200 dias.

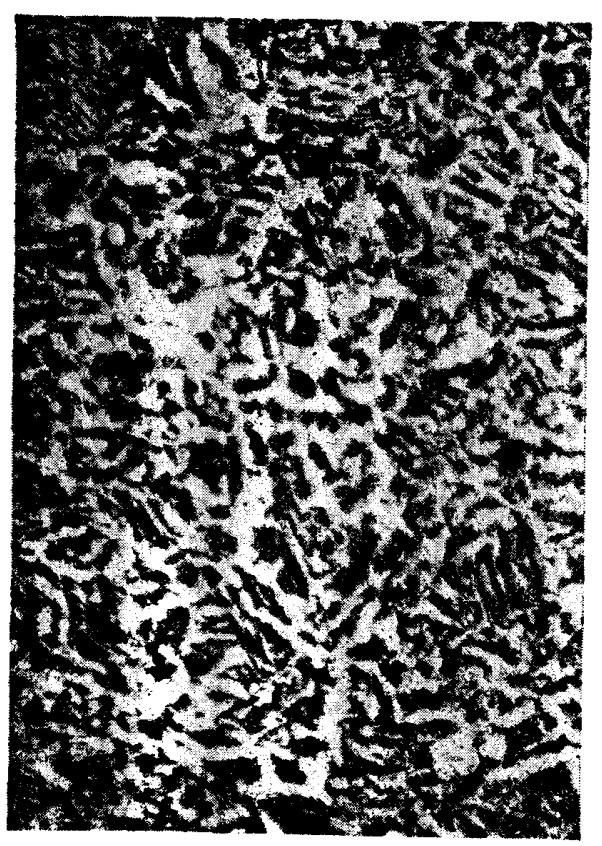

Fig. 19.

Test piece 4C2. Blow no. 306. 200 dias.

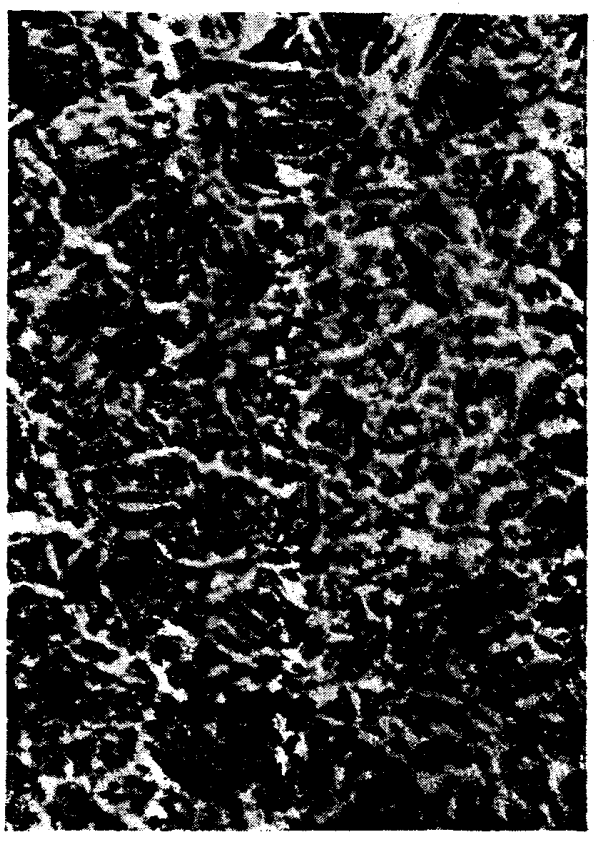

Fig. 20.

Test piece 4C8. Blow no. 318. 200 dias. 